\title{
TRATAMENTO DE FRATURA MANDIBULAR CAUSADA DURANTE EXODONTIA DE SEGUNDO MOLAR
}

Fabiano GALINA, Leandro Eduardo KLUPPEL, Nelson Luis Barbosa REBELLATO, Paulo Roberto MULLER, Delson João Costa

Fraturas mandibulares são freqüentes em serviços de cirurgia $e$ traumatologia bucomaxilofaciais. A etiologia das fraturas são as mais variadas possíveis: acidentes automobilísticos, agressões, acidentes esportivos, dentre outros (REBELLATO NL, 2009). O presente estudo relata o tratamento de uma fratura de mandíbula ocorrida durante a extração de um segundo molar inferior. Uma paciente de 42 anos, gênero feminino, compareceu ao pronto-socorro do Hospital XV, com queixa de dificuldade de abertura bucal e parestesia do nervo alveolar inferior. O quadro se iniciou após a exodontia do elemento 37 por outro profissional. Os exames de imagem (radiografias e tomografia computadorizada) evidenciaram a presença de fratura composta da mandíbula, estendendo-se ao alvéolo do dente 37. O tratamento desta condição foi realizado sob anestesia geral, com redução cirúrgica e fixação interna rígida com uma placa de reconstrução na região de borda inferior de mandíbula, associado a bloqueio maxilo-mandibular trans-operatório. Decorridos cinco meses do procedimento cirúrgico a paciente apresenta recuperação completa da função mandibular e um bom resultado cosmético. Além da apresentação do caso e discussão da abordagem cirúrgica os autores irão discorrer sobre a prevenção deste tipo de intercorrência.

Palavras-Chave: Extração dental; Fratura mandibular; Cirurgia oral. 